\title{
Associated Factors of Quality of Life in First-Episode Schizophrenia Patients
}

\author{
Yun Young Song ${ }^{1,2}$, Kyung Ran Kim ${ }^{1,2}$, Jin Young Park ${ }^{1,2}$, Su Young Lee ${ }^{2,3}$, \\ Jee In Kang ${ }^{2,4}$, Eun Lee ${ }^{1,2}$, Suk Kyoon $\mathrm{An}^{1,2} \otimes$ and Jun Soo Kwon ${ }^{5}$ \\ 1'Department of Psychiatry, Yonsei University College of Medicine, Seoul, Korea \\ 2Section of Affect and Neuroscience, Institute of Behavioural Science in Medicine, Yonsei University College of Medicine, Seoul, Korea \\ ${ }^{3}$ Department of Psychiatry, Cheil General Hospital \& Women's Healthcare Center, Kwandong University College of Medicine, Seoul, Korea \\ ${ }^{4}$ Department of Psychiatry, Ilsan Hospital, National Health Insurance Corporation, Goyang, Korea \\ ${ }^{5}$ Department of Psychiatry, Seoul National University College of Medicine, Seoul, Korea
}

\begin{abstract}
Objective Improving quality of life is an important goal in the treatment of schizophrenia. In previous research, quality of life has been reported to be compromised in patients with schizophrenia. The aim of this study was to investigate whether quality of life may be impaired in first-episode schizophrenia patients and to identify the associated factors of quality of life in first-episode schizophrenia.

Methods Forty-eight patients with first-episode schizophrenia and 20 normal controls were recruited. Quality of life was measured by using the Quality of Life scale (QLS). General and social self-efficacy, perceived social support were measured by using the self-report scales. The clinical assessments and comprehensive neurocognitive battery were also administered.

Results First-episode group showed significantly decreased QLS total and QLS subscale scores compared to normal controls group. The key associated factors of quality of life in patients with first-episode schizophrenia were the negative symptoms and social self-efficacy.

Conclusion This finding implies that compromised quality of life may be already emerged in schizophrenia in their first-episode and the psychosocial interventions should be targeting the negative symptoms and the psychosocial protective factors including self-efficacy in addition to simply ameliorating the positive symptoms to foster social reintegration and recovery of first-episode patients.
\end{abstract}

Psychiatry Investig 2011;8:201-206

Key Words Quality of life, Negative symptoms, Self efficacy, Schizophrenia, First-episode.

\section{INTRODUCTION}

Impairment in quality of life is evident in patients with schizophrenia. ${ }^{1,2}$ Psychiatric treatment for patients with schizophrenia should focus on enhancing patients' quality of life and social integration in addition to simply ameliorating the positive symptoms. ${ }^{3,4}$ Quality of life is a multidimensional construct encompassing not only the subjective domain of life-satisfaction, ${ }^{5}$ but also the objective domains of functional capacity, psychological status, and social interactions. ${ }^{3}$

Received: April 10, 2011 Revised: June 22, 2011

Accepted: July 7, 2011 Available online: August 26, 2011

$\triangle$ Correspondence: Suk Kyoon An, MD

Department of Psychiatry, Severance Mental Health Hospital, Yonsei University Health System 119, 1926 Beon-gil, Gyeongchung-daero, Gwangju 464100 , Korea

Tel: +82-31-760-9404, Fax: +82-31-761-7582, E-mail: ansk@yuhs.ac

(a) This is an Open Access article distributed under the terms of the Creative Commons Attribution Non-Commercial License (http://creativecommons.org/licenses/by$\mathrm{nc} / 3.0$ ) which permits unrestricted non-commercial use, distribution, and reproduction in any medium, provided the original work is properly cited.
Investigating schizophrenia-related determinants of objective quality of life is a pivotal step in elucidating influential factors associated with quality of life and in guiding the development of future interventions designed to promote social integration. ${ }^{6}$ The previous research examining quality of life among patients with schizophrenia has focused mainly on psychopathology and neurocognition. Much of the previous work on quality of life among patients with schizophrenia has shown that the negative symptoms of disorder have a detrimental impact on patients' quality of life, ${ }^{6}$ and this finding in also true for individuals experiencing first-episode schizophrenia. ${ }^{7,8}$ However this relationship might be somewhat inflated as there is significant overlap between negative symptoms and quality of life. ${ }^{9}$ The positive symptoms ${ }^{10}$ have been reported to have minimal impact on quality of life. Neurocognitive impairments have also been reported to be associated with poorer quality of life, especially with respect to level of functional capacity. ${ }^{11,12}$ Two recent large-scale studies in chronic, multi-ep- 
isode schizophrenia patients conducted by different investigators (sample size $=309^{13}$ and $1,386^{14}$ ) revealed that psychopathology and neurocognitive function contribute independently to quality of life among patients with schizophrenia, in spite of the negative symptoms were recalculated to avoid the redundancy of the overlapping between negative symptoms and functional aspects of quality of life. ${ }^{9}$

Additionally, some psychosocial factors have been proposed to be protective factors that serve to optimize quality of life among patients with schizophrenia, and self-efficacy ${ }^{15}$ has also been shown to be associated with Quality of life in schizophrenia.

The aim of this study was to investigate whether quality of life may be impaired in first-episode schizophrenia patients and to identify the associated factors of quality of life in firstepisode schizophrenia.

Based on the previous reports, ${ }^{1,2,6,7,11,12,15}$ we hypothesized that 1) patients with first-episode schizophrenia may show compromised quality of life compared to normal controls, and that 2) quality of life might be associated with negative symptoms of schizophrenia, neurocognitive impairment, and psychosocial protective factors, including self-efficacy and perceived social support.

\section{METHODS}

\section{Participants}

The present study was part of the Green Program for Recognition and Prevention of Early Psychosis (GRAPE) project; the details of this project have been described elsewhere. ${ }^{16-18}$ Forty-eight individuals experiencing first-episode schizophrenia (31 inpatients) were recruited form Severance Hospital and Severance Mental Health Hospital of Yonsei University Health System between May 2007 and November 2010. The duration of psychotic illness was less than 36.0 months except one subject ( 74.0 months) (mean $=10.5, \mathrm{SD}=12.8$, median $=6.0$ months) following the onset of active psychotic symptoms for the first-episode schizophrenia group. All participants met the inclusion criteria of being between 15-35 years old. All schizophrenia patients should be on their stable phase. And in the cases of inpatients, their hospital days were in the range of 3-6 weeks. Participants were evaluated using the Structured Clinical Interview for the DSM-IV. ${ }^{19,20}$ The exclusion criteria were current or past neurological illness or traumatic brain injury for all participants; current or past psychiatric illness for the normal controls; and the number of psychiatric admission more than one or the duration of psychiatric medication more than 15 months for first-episode patients. There was no comorbid substance use disorder in first-episode patients.

The present study was carried out in accordance with the
Declaration of Helsinki. The Institutional Review Boards at Severance Hospital and Severance Mental Health hospital reviewed and approved this study. All participants gave written informed consent.

\section{Measures}

The Heinrichs-Carpenter quality of life scale (QLS) was used to assess the quality of life. The QLS ${ }^{21}$ is a 21 -item semistructured interview used to assess the objective quality of life in patients with schizophrenia. This measure yields a total score and subscores for four domains: 1) intrapsychic foundations (IF; e.g., motivation, curiosity, anhedonia), 2) interpersonal relations (IPR), 3) instrumental role (IR), and 4) common objects and activities (COA). The internal consistencies (alpha) of the total and subdomains score were each greater than 0.79 with the exception of COA $(0.51)$ in the present study.

Self-efficacy was assessed using the Self-efficacy Scale. ${ }^{22}$ The Self-efficacy scale consists of two subscales: general self-efficacy, social self-efficacy. ${ }^{22}$ Perceived social support was measured using the 30-item Interpersonal Support Evaluation List (ISEL), ${ }^{23}$ which includes scales related to belonging, appraisal and information seeking, tangible support, and self-esteem support. The ISEL has been shown to have good psychometric properties among patients with severe psychiatric illness, including schizophrenia. ${ }^{24}$ The internal consistencies (alpha) of the general and social self-efficacy of Self-efficacy Scale and the ISEL in the present study were found to be $0.93,0.82$ and 0.92 , respectively. The presence of psychopathology was evaluated using the Positive and Negative Syndrome Scale (PANSS), ${ }^{25}$ and the Hamilton Depressive (HAM-D) ${ }^{26}$ and Hamilton Anxiety (HAM-A $)^{27}$ scales. In present study, the modified negative syndrome of PANSS were recalculated by omitting three items, including emotional withdrawal, passive/apathetic withdrawal, and difficulty in abstract thinking, which was suggested strategy to avoid the redundancy of common variance between the negative symptoms and QLS scores, by previous studies. ${ }^{13,14}$ Neurocognitive function was assessed using a comprehensive battery that has been described in previous our work. ${ }^{17}$ The scores of each of the assessment measures from the battery were converted to $z$-scores according to our previous larger study ${ }^{17}$ and combined to create a composite global neurocognitive score. The comprehensive battery was composed of the 3-7 Continuous Performance Test ${ }^{28}$ visuospatial and visuo-verbal 2-back test, ${ }^{28}$ WAIS-digit span, ${ }^{29}$ Rey Complex Figure Test, ${ }^{30}$ Immediate and delayed recall scores, California Verbal Learning test (learning trials 1-5, short delay free recall, long delay free recall), ${ }^{31}$ Wisconsin Card Sorting Test ${ }^{32}$ Stroop Test, ${ }^{33}$ Controlled Oral Word Association Test, ${ }^{34}$ Figure Fluency Test, ${ }^{35}$ and the Trail Making Test Part B. ${ }^{36}$ The 
internal consistency of the global neurocognitive score in the present study was 0.90 .

As some of the psychosocial scales and items from the comprehensive neurocognitive battery were not available prior to April 2008, some data of first-episode patients (for Self-efficacy, $n=8$; for ISEL, $n=20$; for HAM-D, $n=1$; for HAM-A, $n=1$ and for neurocognitive battery, $n=12$ ) were not included in the statistical analysis. Some data from the neurocognitive battery were presented elsewhere in order to compare the neurocognitive performance of first-episode groups ${ }^{17}$ with another data of normal controls.

\section{Procedures}

The clinical interviews and assessments were administered by a psychiatrist within a week after recruitment into the study. Each participant received a packet of questionnaires, including the Self-efficacy Scale and Interpersonal Support Evaluation List. The neurocognitive batteries were administered within 2 weeks of recruitment by a masters-level psychologist.

\section{Statistical analysis}

All rated scores had acceptable skewness and kurtosis statis- tics $(<1.0)$. The independent t-tests were done for clinical and socio-demographic variables. Pearson correlations were used to evaluate correlations between QLS scores and the psychopathology, global neurocognitive function, the psychosocial scales. All variables significantly related to QLS total and subdomain scores were analyzed subsequently using a multiple linear regression to evaluate their independent contributions to quality of life. The regression model utilized a stepwise method. The missing data were subjected to pairwise deletion. The criterion for significance was set at $\mathrm{p}<0.05$.

\section{RESULTS}

\section{Participant characteristics}

Demographic and clinical characteristics of the normal controls and first-episode schizophrenia group were presented in Table 1. There were no significant differences between two groups with respect to demographic characteristics. There were significant differences in the general and social self-efficacy, perceived social support, positive, negative and general syndrome of PANSS, HAM-D and HAM-A scale, global neurocognitive score between the two groups.

Table 1. Clinical and demographic characteristics

\begin{tabular}{|c|c|c|}
\hline & Normal controls $(\mathrm{N}=20)$ & FE schizophrenia $(\mathrm{N}=48)$ \\
\hline \multicolumn{3}{|l|}{ Demographic characteristics } \\
\hline Sex: Male/Female & $10 / 10$ & $17 / 31$ \\
\hline Job status: Student/Employed/Unemployed & $9 / 5 / 6$ & $22 / 7 / 19$ \\
\hline Age (years) & $24.1(3.1)$ & $23.7(6.1)$ \\
\hline Education level (years) & $14.5(1.5)$ & $13.7(2.2)$ \\
\hline \multicolumn{3}{|l|}{ Self-rated psychosocial variables } \\
\hline General self-efficacy ${ }^{a}$ & $46.8(8.2)$ & $36.3(12.6)^{*}$ \\
\hline Social self-efficacy ${ }^{a}$ & $13.9(3.2)$ & $11.3(8.3)^{*}$ \\
\hline Perceived social support of ISEL ${ }^{a}$ & $27.7(2.8)$ & $13.6(8.3)^{*}$ \\
\hline \multicolumn{3}{|l|}{ Psychopathologies } \\
\hline Positive syndrome of PANSS & $7.0(0)$ & $17.1(6.0)^{*}$ \\
\hline Negative syndrome of PANSS & $7.5(1.1)$ & $18.6(6.8)^{*}$ \\
\hline Modified Negative syndrome of PANSS & $4.2(0.5)$ & $9.8(4.1)^{*}$ \\
\hline General psychopathology of PANSS & $16.8(2.3)$ & $32.7(9.4)^{*}$ \\
\hline Depressive symptoms of HAM-D ${ }^{\mathrm{a}}$ & $0.9(1.2)$ & $7.5(6.8)^{*}$ \\
\hline Anxiety symptoms of HAM-A ${ }^{a}$ & $1.0(1.3)$ & $7.7(7.3)^{*}$ \\
\hline \multicolumn{3}{|l|}{ Neurocognition $^{a}$} \\
\hline Global neurocognitive score & $0.18(0.4)$ & $-1.02(0.7)^{*}$ \\
\hline Chlorpromazine equivalent dose & & $1,520.0(354.5)$ \\
\hline
\end{tabular}

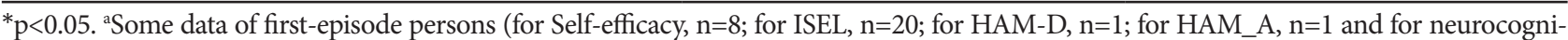
tive battery, $\mathrm{n}=12$ ) were not included in the statistical analysis. ISEL ${ }^{23}$ : Interpersonal Support Evaluation List, PANSS ${ }^{25}$ : Positive and Negative Syndrome Scale; Modified negative syndrome of PANSS were recalculated by omitting three items, including emotional withdrawal, passive/ apathetic withdrawal, and difficulty in abstract thinking, HAM-D: Hamilton Depressive Scale, ${ }^{26}$ HAM-A: Hamilton Anxiety Scale ${ }^{27}$; Chlorpromazine equivalent doses was derived from Kroken et al. ${ }^{39}$ 


\section{Comparison of quality of life between normal controls and first-episode patients}

First-episode group showed significantly decreased QLS total, and across all subscale scores compared to normal controls group (Table 2).

\section{Preliminary analyses in first-episode schizophrenia patients}

The enhanced general self-efficacy, social self-efficacy perceived social support, and neurocognitive performance were correlated to better QLS total and several subdomain scores. Increased severity of modified negative syndrome of PANSS was correlated to poorer QLS total and all subdomain scores (Table 3). Positive syndrome of PANSS, HAM-A and HAM-D

Table 2. Comparison of quality of life between normal controls and first-episode schizophrenia patients

\begin{tabular}{lcc}
\hline & $\begin{array}{c}\text { Normal controls } \\
(\mathrm{N}=20)\end{array}$ & $\begin{array}{c}\text { FE schizophrenia } \\
(\mathrm{N}=48)\end{array}$ \\
\hline Total QLS & $109.4(8.9)$ & $54.8(22.3)^{*}$ \\
Intrapsychic foundation & $37.9(3.5)$ & $19.6(8.7)^{*}$ \\
Interpersonal relations & $41.9(4.5)$ & $19.1(9.7)^{*}$ \\
Instrumental role & $21.1(2.2)$ & $9.8(6.0)^{*}$ \\
Common objects and & $8.6(0.9)$ & $6.3(2.2)^{*}$ \\
activities & & \\
${ }^{*} \mathrm{p}<0.05$. QLS $^{21}$ : Heinrichs-Carpenter Quality of Life Scale
\end{tabular}

were also related to poorer QLS total score and the scores of several subdomains. Outpatients $(\mathrm{n}=17)$ had better QLS score than inpatients $(\mathrm{n}=31)$ in the COA subdivision $(\mathrm{p}=0.008)$. There were no differences according to gender $(p>0.36)$ or employment status $(\mathrm{p}>0.20)$.

\section{Multiple linear regression analyses in first-episode schizophrenia patients}

The modified negative syndrome and social self-efficacy were significant associated factors of QLS total. Modified Negative syndrome was significantly related to the IF subdomain score and social self-efficacy was related to the IPR, IR, COA subdomain scores (Table 4).

\section{DISCUSSION}

The main findings of this study were that the objective quality of life of individuals with first-episode patients group was poorer than normal controls group and the key associated factors of quality of life among individual with first-episode patients group were negative symptoms and social self-efficacy.

Patients with first-episode schizophrenia were found to have poorer quality of life and subdomains of quality of life such as intrapsychic foundation, interpersonal relations, instrumental role and common objects and activities and this is consistent with those of previous studies. ${ }^{1,2}$ This finding means

Table 3. Correlations of quality of life with psychosocial variables, psychopathologies, and neurocognitive function in first-episode patients

\begin{tabular}{|c|c|c|c|c|c|}
\hline & \multicolumn{5}{|c|}{ First episode schizophrenia $(\mathrm{N}=48)$} \\
\hline & Total & IF & IPR & IR & $\mathrm{COA}$ \\
\hline \multicolumn{6}{|l|}{ Demographic variables } \\
\hline Education level (years) & 0.20 & 0.21 & 0.11 & 0.11 & $0.32^{*}$ \\
\hline Duration of illness & -0.19 & -0.11 & -0.18 & $-0.30^{*}$ & 0.07 \\
\hline \multicolumn{6}{|l|}{ Self-rated psychosocial variables } \\
\hline General self-efficacy ${ }^{\mathrm{a}}$ & $0.56^{* *}$ & $0.48^{* *}$ & $0.60^{* *}$ & 0.27 & $0.42^{* *}$ \\
\hline Social self-efficacy ${ }^{a}$ & $0.61^{* *}$ & $0.53^{* *}$ & $0.63^{* *}$ & $0.33^{*}$ & $0.46^{* *}$ \\
\hline Perceived social support of ISEL ${ }^{a}$ & $0.45^{*}$ & $0.38^{*}$ & $0.55^{* *}$ & 0.10 & $0.36^{*}$ \\
\hline \multicolumn{6}{|l|}{ Psychopathology } \\
\hline Positive syndrome of PANSS & $-0.30^{*}$ & $-0.36^{*}$ & -0.23 & -0.09 & $-0.32^{*}$ \\
\hline Modified Negative syndrome of PANSS & $-0.66^{* *}$ & $-0.67^{* *}$ & $-0.59^{* *}$ & $-0.32^{*}$ & $-0.44^{* *}$ \\
\hline Depressive symptoms of HAM-D ${ }^{a}$ & $-0.39^{* *}$ & $-0.35^{*}$ & $-0.34^{*}$ & $-0.31^{*}$ & -0.19 \\
\hline Anxiety symptoms of HAM- $\mathrm{A}^{\mathrm{a}}$ & $-0.38^{* *}$ & $-0.39^{* *}$ & $-0.29^{*}$ & -0.28 & -0.20 \\
\hline \multicolumn{6}{|l|}{ Neurocognitive function ${ }^{a}$} \\
\hline Global neurocognitive function & $0.36^{*}$ & $0.34^{*}$ & $0.35^{*}$ & 0.16 & $0.34^{*}$ \\
\hline
\end{tabular}

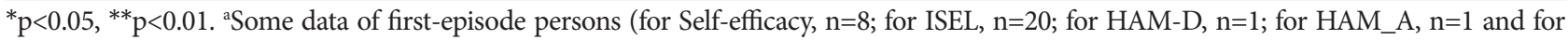
neurocognitive battery, $\mathrm{n}=12$ ) were not included in the statistical analysis. ISEL ${ }^{23}$ : Interpersonal Support Evaluation List, PANSS ${ }^{25}$ : Positive and Negative Syndrome Scale; Modified negative syndrome of PANSS were recalculated by omitting three items, including emotional withdrawal, passive/apathetic withdrawal, and difficulty in abstract thinking, HAM-D ${ }^{26}$ : Hamilton Depressive Scale, HAM- ${ }^{27}$ : Hamilton Anxiety Scale, IF: Intrapsychic Foundations, IPR: Interpersonal relations, IR: Instrumental role, COA: Common Objects and Activities 
Table 4. Stepwise multiple regression analyses of significant factors associated with quality of life in first-episode schizophrenia patients

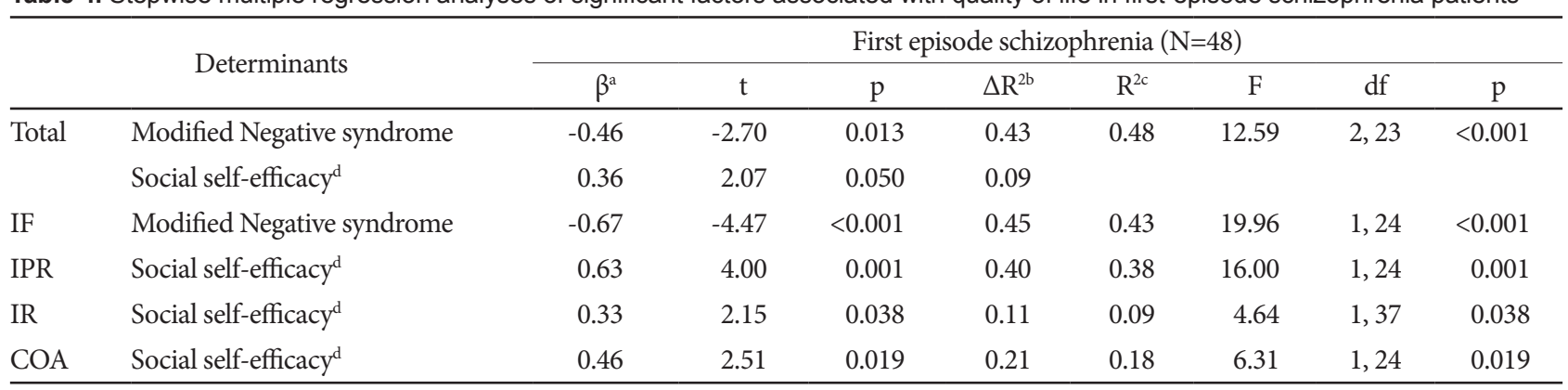

All VIF $<1.5$, all condition index $<10.1$. ${ }^{\text {SStandardized coefficient, }{ }^{\mathrm{b}} \text { Changed variance, } \Delta \mathrm{R}^{2},{ }^{\mathrm{c}} \text { Adjusted } \mathrm{R}^{2} \text {, Explained variance by model, }{ }^{\mathrm{d}} \text { Some }}$ data of first-episode persons (for Self-efficacy, $n=8$ and for ISEL, $n=20$ ) were not included in the statistical analysis. IF: Intrapsychic Foundations, IPR: Interpersonal Relations, IR: Instrumental Role, COA: Common Objects and Activities. Modified Negative syndrome: scores were recalculated by omitting three items, including emotional withdrawal, passive/apathetic withdrawal, and difficulty in abstract thinking of PANSS

that compromised quality of life may be already present in schizophrenia patients in their first-episode.

Negative symptoms were found to be independently contributed to the decreased quality of life total and intrapsychic foundation subdomain in the first-episode patients group. In previous studies, this association was argued to partly reflect some redundancy of common variance between negative symptoms and quality of life for individuals experiencing schizophrenia. ${ }^{7,8}$ In contrast, the present study found an association in spite of recalculation of negative symptoms according to suggested strategy in previous studies ${ }^{13,14}$ to avoid redundancy. In line with previous reports, ${ }^{6-8,13,14}$ quality of life was significantly associated with negative symptoms.

In addition to negative symptoms, social self-efficacy was also independent contributing factor of better quality of life total and across all subdomins in first-episode patients. As a human, intrinsic need such as esteem and self-actualization, ${ }^{3}$ may be unfulfilled due to presence of psychiatric illness, stigma, and related factors. Thus, to promote quality of life, psychosocial interventions should be developed to enhance selfefficacy, especially social one through experience of personal mastery in addition to the reduction of the negative symptoms.

Contrary to our hypothesis, global neurocognitive function and perceived social support were not independent factors of quality of life in first-episode schizophrenia patients. In regard of global neurocognitive function, first, there may be only a modest relationship, which may have gone undetected due to the small sample size of this study. Second, neurocognitive function may not translate into real-world function due to the influence of psychopathology, lack of opportunity, or other factors, which was offered by Narvaez et al. ${ }^{37}$ More plausibly, the impairment in neurocognitive function of this first-episode groups were only 1.0 standard deviation (SD) below the performance of normal controls, which may be not widely re- lated to quality of life. Regarding of perceived social support, the lack of independent contribution to quality of life may be due to that the considerable data (20 of 48) ISEL was not included in statistical analysis.

In regard of affective psychopathology in present study, depression and anxiety was not independent contributing factor of objective quality of life in first-episode schizophrenia patients, although there were significant correlations between QLS and HAM-D, and HAM-A. It may be explained that the affective symptoms in schizophrenia may be nonspecific symptoms since these depression and anxiety symptoms were found to be closely related with the positive $(p<0.010)$ and negative symptoms $(\mathrm{p}<0.12)$ and self-efficacy $(\mathrm{p}<0.005)$.

The limitations of this study should be addressed. First one was the small sample sized and cross-sectional nature, which precludes conclusions regarding causality. In addition, some data including ISEL and global neurocognitive function were not included into statistical analysis. In the near future, longitudinal follow-up studies with larger samples with full data set will be needed to elucidate the key determinants of quality of life among individuals with first-episode schizophrenia. Second, in present study, there was no measurement of subjective quality of life. It was reported that in schizophrenia patients, the subjective rating of quality of life may be valid and informative on the point of life satisfaction. ${ }^{38}$ Hence, future study aiming to further explore this issue of determinants of subjective and objective quality of life will be needed in the first-episode schizophrenia patients. Finally, other variables such as level of insight, and side effect of antipsychotic medications were not included in the present study, which may be confounding effects on the relationship. ${ }^{38}$

In conclusion, the present study found that quality of life may be already compromised in schizophrenia patients in their early phase. More importantly, the key independent contributing factors of objective quality of life may be negative 
symptoms and psychosocial protective factors of social selfefficacy in individuals with first-episode schizophrenia. This finding implies that for social reintegration and recovery, psychosocial interventions should be comprehensive, targeting negative symptoms and self-efficacy in addition to simply ameliorating the positive symptoms.

\section{Acknowledgments}

This study was supported by a grant of the Korea Healthcare technology R\&D project, Ministry for Health, Welfare and Family Affairs, Republic of Korea (A090096).

\section{REFERENCES}

1. Alptekin K, Akvardar Y, Kivircik Akdede BB, Dumlu K, Işik D, Pirinçci $\mathrm{F}$, et al. Is quality of life associated with cognitive impairment in schizophrenia? Prog Neuropsychopharmacol Biol Psychiatry 2005;29:239-244.

2. Woon PS, Chia MY, Chan WY, Sim K. Neurocognitive, clinical and functional correlates of subjective quality of life in Asian outpatients with schizophrenia. Prog Neuropsychopharmacol Biol Psychiatry 2010; 34:463-468.

3. Katschnig H. Schizophrenia and quality of life. Acta Psychiatr Scand Suppl 2000;407:33-37.

4. Hopper K. Rethinking social recovery in schizophrenia: what a capabilities approach might offer. Soc Sci Med 2007;65:868-879.

5. Malla A, Payne J. First-episode psychosis: psychopathology, quality of life, and functional outcome. Schizophr Bull 2005;31:650-671.

6. Eack SM, Newhill CE. Psychiatric symptoms and quality of life in schizophrenia: a meta-analysis. Schizophr Bull 2007;33:1225-1237.

7. Browne S, Clarke M, Gervin M, Waddington JL, Larkin C, O'Callaghan E. Determinants of quality of life at first presentation with schizophrenia. Br J Psychiatry 2000;176:173-176.

8. Addington J, Young J, Addington D. Social outcome in early psychosis. Psychol Med 2003;33:1119-1124.

9. Goutevitch R, Abbadi S, Guelf JD. Quality of life in schizophrenics with and without the deficit syndrome. Eur Psychiatry 2004;19:172-174.

10. Ho BC, Nopoulos P, Flaum M, Arndt S, Andreasen NC. Two-year outcome in first-episode schizophrenia: predictive value of symptoms for quality of life. Am J Psychiatry 1998;155:1196-1201.

11. Addington J, Saeedi H, Addington D. The course of cognitive functioning in first episode psychosis: changes over time and impact on outcome. Schizophr Res 2005;78:35-43.

12. Green MF, Kern RS, Braff DL, Mintz J. Neurocognitive deficits and functional outcome in schizophrenia: are we measuring the "right stuff"? Schizophr Bull 2000;26:119-136.

13. Perlick DA, Rosenheck RA, Kaczynski R, Bingham S, Collins J. Association of symptomatology and cognitive deficits to functional capacity in schizophrenia. Schizophr Res 2008;99:192-199.

14. Mohamed S, Rosenheck R, Swartz M, Stroup S, Lieberman JA, Keefe RS. Relationship of cognition and psychopathology to functional impairment in schizophrenia. Am J Psychiatry 2008;165:978-987.

15. Ritsner M, Kurs R, Gibel A, Hirschmann S, Shinkarenko E, Ratner Y. Predictors of quality of life in major psychoses: a naturalistic follow-up study. J Clin Psychiatry 2003;64:308-315.

16. An SK, Kang JI, Park JY, Kim KR, Lee SY, Lee E. Attribution bias in ultra-high risk for psychosis and first-episode schizophrenia. Schizophr Res 2010;118:54-56.

17. Kim KR, Park JY, Song DH, Koo HK, An SK. Neurocognitive performance in subjects at ultra-high risk for schizophrenia: a comparison with first-episode schizophrenia. Compr Psychiatry 2010;52:33-40.
18. Lee SY, Namkoong K, Cho HH, Song DH, An SK. Reduced visual P300 amplitudes in individuals at ultra-high risk for psychosis and first-episode schizophrenia. Neurosci Lett 2010;486:156-160.

19. First MB, Gibbon M, Spitzer RL, Williams JBW. Structured Clinical Interview for DSM-IV Axis I Disorders: Non-Patients Edition (SCID-I/ PS), Version 2. New York: New York State Psychiatric Institute, Biometrics Research; 1996.

20. First MB, Gibbon M, Spitzer RL, Williams JBW. Structured Clinical Interview for DSM-IV Axis I Disorders: Patient Edition (SCID-I/P), Version 2. New York: New York State Psychiatric Institute, Biometrics Research; 1996.

21. Heinrichs DW, Hanlon TE, Carpenter WT Jr. The quality of life scale: an instrument for rating the schizophrenic deficit syndrome. Schizophr Bull 1984;10:388-398.

22. Sherer M, Maddux JE, Mercandante B, Prentice-Dunn S, Jacobs B, Rogers RW. The self-efficacy scale: construction and validation. Psychol Rep 1982;51:663-671.

23. Cohen S, Wills TA. Stress, social support, and the buffering hypothesis. Psychol Bull 1985;98:310-357.

24. Rogers ES, Anthony W, Lyass A. The nature and dimensions of social support among individuals with severe mental illnesses. Community Ment Health J 2004;40:437-450.

25. Kay SR, Fiszbein A, Opler LA. The positive and negative syndrome scale (PANSS) for schizophrenia. Schizophr Bull 1987;13:261-276.

26. Hamilton M. Rating depressive patients. J Clin Psychiatry 1980;41:2124.

27. Hamilton M. The assessment of anxiety states by rating. Br J Med Psychol 1959;32:50-55.

28. Nuechterlein KH, Edell WS, Norris M, Dawson ME. Attentional vulnerability indicators, thought disorder, and negative symptoms. Schizophr Bull 1986;12:408-426.

29. Wechsler D. Wechsler Adult Intelligence Scale-Revised. New York: The Psychological Corporation; 1981.

30. Rey A. L'examen Clinique en Psychologie. Paris : Presses Universitaires de France; 1964.

31. Delis DC, Kramer JH, Kaplan E, Ober BA. California Verbal Learning Test Manual. San Antonio, TX: The Psychological Corporation; 1987.

32. Heaton RK, Chelune GJ, Talley JL, Kay GG, Curtiss G. Wisconsin Card Sorting Test Manual-Revised and Expanded. Odessa, FL: Psychological Assessment Resources, Inc; 1993.

33. Golden CJ. Stroop Color and Word Test: Manual for Clinical and Experimental Uses. Chicago, IL: Stoelting Co; 1978.

34. Spreen O, Benton AL. Neurosensory Center Comprehensive Examination for Aphasia (NCCEA). Victoria, British Columbia: Neuropsychology Laboratory, University of Victoria; 1969.

35. Ruff RM, Light RH, Evans RW. The ruff figural fluency test: a normative study with adults. Dev Neuropsychol 1987;3:37-51.

36. Reitan R. Manual for Administration of Neuropsychological Test Batteries for Adults and Children. Tucson, AZ: Reitan Neuropsychology Laboratories, Inc; 1979.

37. Narvaez JM, Twamley EW, McKibbin CL, Heaton RK, Patterson TL. Subjective and objective quality of life in schizophrenia. Schizophr Res 2008;98:201-208.

38. Jung HY, Hwang SS, Yi JS, Kim Y, Kim YS. Clinician-rated function and patient-rated quality of life in schizophrenia: implications of their correspondence for psychopathology and side effects. Prog Neuropsychopharmacol Biol Psychiatry 2010;34:225-230.

39. Kroken RA, Johnsen E, Ruud T, Wentzel-Larsen T, Jørgensen HA. Treatment of schizophrenia with antipsychotics in Norwegian emergency wards, a cross-sectional national study. BMC Psychiatry 2009;9:24. 